\title{
Reactivity of isocyanates with urethanes: Conditions for allophanate formation.
}

\author{
A. Lapprand ${ }^{a^{*}}$, F. Boisson ${ }^{b}$, F. Delolme ${ }^{c}$, F. Méchin ${ }^{\mathrm{a}}$, J-P. Pascault ${ }^{\mathrm{a}}$ \\ ${ }^{a}$ Laboratoire des Matériaux Macromoléculaires, UMR CNRS n ${ }^{\circ} 5627$. \\ INSA, Bât. Jules Verne, 20 avenue A. Einstein, \\ 69621 Villeurbanne Cedex, France. \\ ${ }^{b}$ Service de RMN. FR 2151 / CNRS. BP 24, 69390 Vernaison, France. \\ ${ }^{c}$ Service Central d'Analyse, Spectrométrie de Masse BP22, 69390 Vernaison, France.
}

\begin{abstract}
The reactions between two polyisocyanates, 4,4'-methylenebis(phenyl isocyanate) (MDI) and trimer of isophorone diisocyanate (tIPDI) and a model aryl-alkyl diurethane were carried out at high temperature $\left(\geq 170^{\circ} \mathrm{C}\right.$ ) and several $\mathrm{NCO} /$ urethane ratios. A combination of ${ }^{1} \mathrm{H} \&{ }^{13} \mathrm{C}$ NMR and MALDI-TOF spectroscopies was used and allows the identification of reaction products. When MDI or tIPDI is reacted with a diurethane at high temperature and after cooled, allophanates are formed but no isocyanurates. ${ }^{13} \mathrm{C}$ NMR was used to quantify the different reaction products obtained under different experimental conditions. Only a few allophanates $(\leq 10 \%)$ are obtained after $1 \mathrm{~h}$ of reaction.
\end{abstract}

Keywords: Urethane; allophanate; NMR; MALDI-TOF

Published in Polymer Degradation and Stability, vol. 90, 363-373 (2005)

${ }^{*}$ Corresponding author. Tel.: +33-472-43-60-03: fax: +33-472-43-85-27. E-mail address: aude.lapprand@insa-lyon.fr (A. Lapprand) 


\section{Introduction}

The chemistry of polyurethanes rests above all on the reactions between alcohol and isocyanate, which have been widely studied[1]. The formation of urethane groups results from the addition between isocyanates and alcohols, with kinetics depending on the nature of the two reagents and of the solvent. The electronic effects of substituents on the reactivity of isocyanates are of great importance, since it was shown that phenyl isocyanate was fifty times more reactive than ethyl isocyanate with respect to methanol[2]. The effect of solvent[3-5] on the rate of the isocyanate-alcohol reaction was also confirmed, the rate of reaction decreasing approximately in order of the increasing dielectric constant of the solvent and the ability of the solvent to hydrogen bond with alcohol.

In addition, a number of side reactions may take place depending upon the reaction conditions such as the temperature, the ratio between alcohol and isocyanate, and the presence of catalyst (Fig 1). These side reactions result in the formation of allophanates and isocyanurates under special conditions, together with ureas and biurets if there are traces of water during the reaction (Fig 2)

The determination of allophanate and biuret has been of great interest. Kogon[6-8] followed the disappearance of the absorption band in the near infrared to study the formation of allophanate in the reaction of urethane with aryl isocyanate. Furukawa and Yokoyama[9] used aliphatic primary amine to distinguish the allophanate and the biuret from carbamate and disubstituted urea due to the selective degradation of allophanate and biuret by this amine. Sumi et al.[10] showed that urea, urethane, allophanate and biuret linkages exhibited their own characteristic chemical shifts in ${ }^{1} \mathrm{H}$ NMR spectra. Okuta[11] dissolved the formed polyurethane networks in dimethylsulfoxide, DMSO and dimethylacetamide, DMAc, by degrading the allophanate and biuret linkages with aliphatic primary amine followed by NMR analysis of the degradation products to yield quantitative information about crosslinks. Spirkova et al.[12] and Schwetlick et al.[3] used HPLC to identify the reaction products with model compounds, in the same way as Sebenik[13] with SEC and ${ }^{13} \mathrm{C}$ NMR.

According to Spirkova, no secondary reactions[12] can occur at room temperature without catalyst. At $50^{\circ} \mathrm{C}$, in acetonitrile, Schwetlick[3] identified 3 different reaction conditions: at equimolar $\mathrm{NCO} / \mathrm{OH}$ ratios, with or without catalysts like tin carboxylates and common tertiary amines, urethane is the main product when isocyanates react with alcohols, the kinetic rate constants are in the order $\mathrm{k}_{\mathrm{a}} \gg \mathrm{k}_{\mathrm{b}} \approx \mathrm{k}_{\mathrm{c}}$ (see Fig 1 for the reactions). At equimolar NCO/OH ratios, and with catalysts such as aminals, aminoalcohols, amidines and carboxylate, phenolate and alkoxide anions, the order of rate constants is $\mathrm{k}_{\mathrm{a}}<\mathrm{k}_{\mathrm{b}} \approx \mathrm{k}_{\mathrm{c}}$. In the same way, at high $\mathrm{NCO} / \mathrm{OH}$ ratios, isocyanurate is the only final product formed via the urethane and allophanate as detectable intermediates.

At $130^{\circ} \mathrm{C}$, and with a $\mathrm{NCO} / \mathrm{OH}$ ratio of 4 , Sebenik et al.[13] found that the kinetic rate constant for the formation of allophanates from isocyanates and polyols lied in the range 4-7.10 ${ }^{-5}$ L.mol ${ }^{-1} \cdot \mathrm{s}^{-1}$. Kogon[8] found that at $100-140^{\circ} \mathrm{C}$, the rate constant of ethyl- $\alpha, \gamma$-diaryl allophanates increased from $1.0 .10^{-6}$ to $6.0 .10^{-6} \mathrm{~L}_{\mathrm{mol}} \mathrm{mol}^{-1} \cdot \mathrm{s}^{-1}$. The allophanate formed was an intermediate reaction product in the formation of isocyanurate when the equilibrium of the phenyl isocyanate/ethyl urethane reaction $(\mathrm{NCO} /$ urethane $=12.6)$ was approached.

Allophanate can dissociate, ending to the reformation of urethane and isocyanate. The stability of allophanate depends on the type of structure and on temperature. By using model aliphatic, cycloaliphatic and aromatic compounds, it was shown[14, 15] that aromatic allophanates are the least stable compounds and dissociate to a considerable extent, even if heated for a short 
time only $\left(10 \mathrm{~min}\right.$ at $\left.165-210^{\circ} \mathrm{C}\right)[16]$. The rate of allophanate dissociation observed by Kogon[17] increases with temperature, from $0.39 .10^{-4}$ to $1.65 .10^{-4} \mathrm{~s}^{-1}$ at 132 to $150^{\circ} \mathrm{C}$. According to Parodi[1], the fact that measurable dissociation occurred at $106^{\circ} \mathrm{C}$ shows that the allophanate crosslink would be relatively unstable.

The dissociation of allophanates is due to the reversible character at high temperature of the addition reactions of isocyanate with compounds that have active hydrogens. This proceeds by the same mechanism as the dissociation of the urethane linkages. Bayer[18] reported the upper stability temperature for different urethane groups shown in Table 1.

Yang et al.[19], in the same way as Camberlin and Pascault[20], studied the dissociation of urethanes synthesized from 4,4'-diphenyl-methane diisocyanate and 1,4-butanediol. These urethanes were found to dissociate thermally to free isocyanate and alcohol at elevated temperatures. Degradation is possible even in the solid state if annealing time is long enough, i.e. 2 hours at $170^{\circ} \mathrm{C}$. One may expect a most probable molar mass distribution after the random scission process during the degradation and the random reformation of urethanes during cooling. In any experiment involving urethanes heated at high temperatures, the possibility of degradation must be taken into account.

In this study, the reactivity of the urethane linkage with polyisocyanates at high temperature has to be known. Lu et al.[21] investigated reactions between urethanes and many functional compounds, except isocyanates. A model urethane compound, dioctyl 4,4'-methylenebis(phenyl carbamate) (OMO) was synthesized by capping 4,4'-methylenebis(phenyl isocyanate) (MDI) with $n$-octanol, in the same way as Lu et al. (Fig 3). This low molar mass diurethane was reacted with either MDI, or trimer of isophorone diisocyanate (tIPDI) by varying 2 parameters, stoichiometry and temperature.

The products of the reaction between OMO and MDI or t.IPDI have been characterized by SEC, ${ }^{1} \mathrm{H}$ and ${ }^{13} \mathrm{C}$ NMR and MALDI-TOF, in order to be able to anticipate the results of a further grafting experiment involving a thermoplastic polyurethane, TPU, and MDI or tIPDI.

The final aim of this work is indeed to perform and to control the chemical modification of TPUs in order to obtain polymers that can be self-crosslinked after processing, for better thermomechanical characteristics by grafting isocyanates on the urethane units of TPU chains and thus introducing new reactive groups able to post-react[22, 23].

\section{Experimental}

\subsection{Analytical techniques.}

Size exclusion chromatography (SEC) was performed in THF, using a Waters chromatograph equipped with 3 microstyragel columns and a refractive index detector. The column calibration was done referring to polystyrene standards.

High-resolution liquid NMR spectroscopy was carried out with a Bruker DRX 400 spectrometer operating at $400 \mathrm{MHz}$ for ${ }^{1} \mathrm{H}$ and $100.6 \mathrm{MHz}$ for ${ }^{13} \mathrm{C}$. Spectra were obtained with a $5 \mathrm{~mm}-$ QNP probe at $298 \mathrm{~K}$. Deuterated chloroform, $\mathrm{CDCl}_{3}$, or dimethylsulfoxide, DMSO-d6, were used as solvents. Chemical shifts values are given in ppm with reference to internal tetramethylsilane.

All mass spectra were obtained using a MALDI-TOF Voyager-DE STR (Applied Biosystems) equipped with a nitrogen laser emitting at $337 \mathrm{~nm}$. Samples were dissolved in THF or DMSO and 
mixed with Dithranol as matrix and $\mathrm{NaI}$ as cationization agent $(10 / 1 / 1, \mathrm{v} / \mathrm{v} / \mathrm{v})$. An aliquot of $1 \mu \mathrm{L}$ of the resulting mixture was spotted on the MALDI sample plate and air-dried.

\subsection{Materials.}

Octanol was purchased from Riedel-deHaën and used as received.

MDI, provided by Huntsman (Suprasec 1100) contains $\sim 98 \%$ of 4,4' diphenylmethane diisocyanate and $\sim 2 \%$ of $2,4^{\prime}$ diphenylmethane diisocyanate with $\mathrm{Tf}=38^{\circ} \mathrm{C}$. It was kept at $4^{\circ} \mathrm{C}$, in order to prevent dimer formation.

OMO was synthesized according to a previously published procedure[21] and characterized by ${ }^{1} \mathrm{H}$ and ${ }^{13} \mathrm{C}$ NMR. The melting point of OMO was found by $\mathrm{DSC}$ between 117 and $120^{\circ} \mathrm{C}$, as reported by Lu et al.[21].

The trimer of IPDI, supplied by Degussa (Vestanat $\mathrm{T}$ 1890/100) is an amorphous polyisocyanate, with a $\mathrm{Tg}=70^{\circ} \mathrm{C}$. According to a recent publication[24], the so-called trimer of IPDI is formed by many oligomers, not only trimer but also pentamer, heptamer or higher molar mass oligomers of IPDI (Fig 4), resulting from condensation of isophorone diisocyanate. (Fig.5)

\subsection{OMO modification.}

OMO was mixed with MDI or IPDI trimer in a reaction flask at temperatures between $160^{\circ} \mathrm{C}$ and $210^{\circ} \mathrm{C}$, under argon, using varying isocyanate/urethane ratios, $\mathrm{i} / \mathrm{u}$. At various reaction times, samples were removed and quenched in an ice-water bath. One part was then dissolved in tetrahydrofuran (THF) with $0.5 \% \mathrm{w} / \mathrm{w}$ secondary amine (diethylamine or di $n$-butylamine). The secondary amines are expected to react and neutralize the unreacted NCO. Both neutralized and non neutralized samples have been analyzed.

\section{Results and discussions.}

\subsection{Urethane dissociation and OMO stability.}

Urethanes are known to dissociate at high temperature, the reversible degradation releases free isocyanate and alcohol (Fig.1-a). After heating at $180^{\circ} \mathrm{C}$, even during 1 hour, the SEC chromatogram of OMO after cooling back to room temperature shows no difference. When heating at $210^{\circ} \mathrm{C}$, the SEC curves indicate a decrease in OMO concentration while at this temperature, octanol is partially volatilized. It means that even if all OMO molecules could be dissociated at $180^{\circ} \mathrm{C}$, alcohol and isocyanate functions would remain in stoichiometric ratio and during cooling, the $\mathrm{NCO}+\mathrm{OH}$ reaction would be favored, and $\mathrm{OMO}$ reformed. But when heating at $210^{\circ} \mathrm{C}$, alcohol and isocyanate are no longer in stoichiometry and the total amount of OMO can not be recovered after cooling.

Furthermore, using the same model diurethane Lu et al.[21] showed that only $1 \%$ of urethane was converted after $60 \mathrm{~min}$ at $200^{\circ} \mathrm{C}$.

\subsection{Method for analysis of the reaction products between OMO and isocyanates.}

When OMO is heated with an isocyanate, MDI or tIPDI at high temperature, in the range 170$200^{\circ} \mathrm{C}$, the $\mathrm{OMO}$ dissociation reaction occurs; but as there is now excess isocyanate groups, during cooling down to room temperature for analysis and according to Figure 1, four main reactions can be expected. 
When reacting isocyanates with alcohols, studies[3-5, 25, 26] have shown that side reactions are favored in solution and consequently the choice of the solvent to use for NMR analysis is a real problem. By calculating rate constants for the primary and secondary reactions, the results of Anzuino et al.[25] checked the hypothesis of allophanate formation in dimethylacetamide, without catalyst, at $10-30^{\circ} \mathrm{C}$. Authors found that the allophanate/urethane ratio increased with increasing $[\mathrm{NCO}] /[\mathrm{OH}]$ ratio and temperature. Moreover, an isocyanate compound is not stable in this solvent, since Matsui[26] showed the cyclization of the isocyanate group in DMAc at $40^{\circ} \mathrm{C}$. Matsui et al. demonstrated that trimerization, which is known to be catalyzed by bases or metals, could take place slowly even without catalyst. They supposed that DMAc, as a slightly basic solvent, might enhance the reaction, being itself a catalyst.

In the first step of the study, NMR analysis of non-neutralized samples was carried out with DMSO-d6 as solvent.

In the $\mathrm{C}=\mathrm{O}$ region of the ${ }^{13} \mathrm{C}$-NMR spectra for non-neutralized samples, isocyanurate functions were identified by their resonances at $149.03 \mathrm{ppm}$. According to literature $[13,27]$, the other four peaks have been attributed to the $\mathrm{C}=\mathrm{O}$ groups from urethane $(153.67 \mathrm{ppm})$, allophanate $(154.88$ ppm and $151.06 \mathrm{ppm}$ ), and aryl-aryl urea ( $152.57 \mathrm{ppm}$ ) functions (see Figure 6-b).

A detailed study showed that the samples changed very quickly (less than one hour) in DMSOd6, at room temperature, without any catalyst. These side reactions lead to the disappearance of allophanate functions, the appearance of isocyanurates while no isocyanurate functions are present in the unchanged sample as shown in Figure 6.

Even for an unreacted sample of OMO + MDI, comparing the ${ }^{1} \mathrm{H}$ NMR spectrum recorded before and after a ${ }^{13} \mathrm{C}$ NMR acquisition, it was shown that the time required for the ${ }^{13} \mathrm{C} N M R$ experiment was sufficient to permit the formation of allophanates, because of the reaction of urethanes with isocyanates, at $25^{\circ} \mathrm{C}$, in DMSO-d6. The ${ }^{13} \mathrm{C}$ NMR spectrum also indicates the presence of isocyanurate groups, which are present neither in the OMO spectrum nor in the MDI spectrum, but result from a reaction between both during the acquisition.

As assumed by Anzuino et al.[25] and Matsui et al.[26], the polar character of the solvent might be responsible for the relatively fast secondary reactions occurring in DMSO-d6. It should be noticed than the time required for the acquisition of the ${ }^{13} \mathrm{C}$ NMR spectrum is incompatible with the rapid evolution of the non neutralized products in DMSO-d6, contrary to some literature indications[28]. Once again, the high reactivity of isocyanate groups is pointed out as the necessity to neutralize the unreacted functions before analysis.

$\mathrm{CDCl}_{3}$, which is less polar, was then used to follow the reaction as the products were shown not to develop in this solvent. On the other hand, with this solvent, the NH proton signals were no more attributable because their resonances were very close to those of aromatic protons. The most suitable method was then found to carry out ${ }^{1} \mathrm{H}$ NMR analysis in DMSO-d6 and to use $\mathrm{CDCl}_{3}$ for ${ }^{13} \mathrm{C}$ NMR analysis.

Furthermore, a comparative NMR analysis of both neutralized and non neutralized samples has been achieved using these conditions in order to ensure that neutralization by a secondary amine did not degrade the products of reaction. 


\subsection{Reaction between the diurethane OMO and the aromatic isocyanate, MDI}

The reactions were carried out at $\mathrm{T}=170-200^{\circ} \mathrm{C}$ and the samples cooled to room temperature and neutralized or not by a secondary amine for different analyses.

A SEC chromatogram is given in Fig.7. SEC peaks of both starting materials (OMO and MDI) are formally identified, and decrease during reactions while new peaks corresponding to compounds of higher molar masses appear and increase. Assumptions were made about these peaks, but to clearly identify the reaction products, a combination of ${ }^{1} \mathrm{H} \&{ }^{13} \mathrm{C}$ NMR and MALDITOF spectroscopies was used and appears very useful.

Enlargements of the $\mathrm{C}=\mathrm{O}$ regions (b) and the $\mathrm{NH}$ regions (a) of ${ }^{13} \mathrm{C}$ and ${ }^{1} \mathrm{H}$ NMR spectra, respectively are shown in Figure 8 for a OMO+MDI mixture with equimolar NCO/urethane ratio, heated at $192^{\circ} \mathrm{C}$ for 60 minutes.

As mentioned before, three main peaks are observed in the $\mathrm{C}=\mathrm{O}$ region of the ${ }^{13} \mathrm{C}-\mathrm{NMR}$ spectra for the non-neutralized sample corresponding to urethane $(153.91 \mathrm{ppm})$ and allophanate (151.67 and $165.10 \mathrm{ppm}$ ). These functions are also characterized by their NH proton resonances found in DMSO-d6 at $9.50 \mathrm{ppm}$ for urethane and $10.65 \mathrm{ppm}$ for allophanate.

Thanks to NMR analysis, allophanates have been identified as the main functions formed during the reaction between the low molar mass diurethane OMO and MDI at high temperature. No isocyanurate has been found as reaction product.

A complementary study was achieved by MALDI-TOF since this technique allows the separation and the identification of the reaction products according to their molar mass. However, the same molar mass could correspond to different molecules. When the sample is neutralized by a solution with a secondary amine, an increase in the molar mass is observed in the molecules carrying one or many unreacted isocyanates. That is why comparing the spectrum of non neutralized and neutralized sample allows the clear identification of the reaction product.

The formation of many monourethanes $(\mathrm{OM})$, which are generated by the dissociation of the urethane bond of OMO in presence of excess isocyanate is showed at $\mathrm{m} / \mathrm{z}, 403.4$ (Fig.9).

Numerous compounds of higher molar masses have been identified as grafted di- or monourethanes. These grafted molecules are the result of reactions between urethane bonds and isocyanates, ending in allophanate linkages. Those molecules can further react, with dissociated alcohol for example, ending to branched molecules.

NMR and MALDI-TOF lead to the same conclusions, since only compounds involving allophanate bonds are found, and no molecules carrying isocyanurate linkages. Compared to the literature, it is a surprising result as it was not expected to form allophanate during reaction at such high temperatures. Moreover, many authors have considered this function as an intermediate reaction product in the formation of isocyanurate. In our reaction conditions, i.e. equimolar $\mathrm{NCO} /$ urethane ratio and temperature between 170 and $200^{\circ} \mathrm{C}$, no isocyanurate is observed even after one hour of reaction.

\subsection{Reaction between the diurethane OMO and the aliphatic isocyanate tIPDI}

The study of OMO reacted with tIPDI becomes more complicated, partly because of the various components (trimer, pentamer, heptamer, etc... of IPDI) of the polyisocyanate. Moreover, it should 
be noticed here that the IPDI molecule as the corresponding IPDI "trimer" exhibits two different isocyanate groups. Consequently, in the ${ }^{13} \mathrm{C}$ NMR spectrum of tIPDI, two different peaks can be observed, according to the aliphatic or cycloaliphatic nature of the isocyanate groups and also different isocyanurate signals are observed according to the nature of the isocyanate groups involved in these functions[29-32].

After the reaction of $\mathrm{OMO}$ with $\mathrm{tIPDI}$, at $\mathrm{T}=\left[170-200^{\circ} \mathrm{C}\right]$ and $[\mathrm{NCO}] /[$ urethane $]=[0.5-1]$ for $60 \mathrm{~min}$, the ${ }^{13} \mathrm{C}$ NMR spectrum (Fig.10) reveals the presence of five main signals in the carbonyl region : according to literature[13, 24, 30, 33], the signals at 149.70 and $150.52 \mathrm{ppm}$ are attributed to the $\mathrm{C}=\mathrm{O}$ from isocyanurates. The signal at $154.08 \mathrm{ppm}$ comes from the $\mathrm{C}=\mathrm{O}$ of urethane. The $\mathrm{C}=\mathrm{O}$ resonances from alkyl-alkyl urea are found at 156.66 and $157.40 \mathrm{ppm}$.

Four minor signals are also detectable at $156.05 \mathrm{ppm}, 155.77 \mathrm{ppm}, 154.68 \mathrm{ppm}$ and 153.61 ppm.

Depending on the nature of the isocyanate that reacts with the urethane, two different allophanates can be expected (Fig.11). Each allophanate function contains two carbonyl groups, one coming from the initial urethane function, and the other coming from the isocyanate function. Considering that the chemical shifts of the $\mathrm{C}=\mathrm{O}$ coming from urethane $\left(\mathrm{C}_{11 \mathrm{~b}}\right.$ and $\mathrm{C}_{12 \mathrm{~b}}$ in Fig.11) are expected to be close to one of the allophanate functions from OMO+MDI, meaning close to 156.10 ppm, the peaks at 155.77 and 156.05 ppm were putatively attributed to $C_{11 b}$ and $C_{12 b}$.

The signals at 153.61 and $154.68 \mathrm{ppm}$ were then attributed to either $\mathrm{C}_{11 \mathrm{a}}$ or $\mathrm{C}_{12 \mathrm{a}}$. It is interesting to notice that signals at 155.77 and $153.61 \mathrm{ppm}$, like signals at 156.10 and $154.68 \mathrm{ppm}$, have very close integral values so that they should belong to the same allophanate function.

It is difficult by NMR to be sure that no isocyanurate functions have been formed during reaction since the corresponding carbonyl signals are expected to be close to those of the starting tIPDI. However a quantitative exploitation of the ${ }^{13} \mathrm{C}$ NMR spectra (recorded with an inversegate decoupling sequence and a pulse delay of $11.4 \mathrm{~s}$ and a pulse angle $70^{\circ}$ ) shows that the ratio between the integral of isocyanurate signals and the integral of the carbons labeled $8+8$ ' (not involved in the reactions) does not change significantly while heating.

The MALDI-TOF analysis confirms the absence of molecules involving isocyanurate bonds, but indicates the formation of many grafted diurethanes, via allophanate linkages. These molecules can further react with dissociated alcohol. It should be noticed that the different oligomers of IPDI (pentamer, heptamer etc...) have also reacted with the diurethane OMO. As discussed latter, the main difference in OMO + MDI versus OMO + tIPDI reactions observed by MALDI-TOF is the weakness of the peak corresponding to the monourethane $(\mathrm{OM})$.

\subsection{Comparison between OMO reactions with MDI and tIPDI}

From a quantitative analysis of the signals found in the carbonyl region of the ${ }^{13} \mathrm{C}$ NMR spectra, it was possible to follow the evolution of the amount of urea, urethane and allophanate functions produced or consumed in both reactions versus time (Fig.12). As expected, isocyanates and urethanes are consumed at the same rate during the reaction. However, only few allophanates are obtained, approximately $10 \%$ after 1 hour of an OMO + MDI reaction. In the case of a reaction of OMO + tIPDI in the same conditions of stoichiometry and temperature, even less allophanates are formed. However, another experiment at $200^{\circ} \mathrm{C}$ (figure not represented here) showed that the quantity of allophanate produced by the reaction of OMO + tIPDI increased with temperature. 
The main difference between the behavior of OMO + MDI and OMO + tIPDI reactions is the quantity of monourethane evidenced during SEC analysis.

Comparing OM peaks from SEC chromatograms for an OMO + MDI mixture and an OMO + tIPDI mixture (Fig.13), at equimolar isocyanate over urethane ratios, it is noteworthy that much more monourethanes OM are obtained when MDI is reacted with OMO.

It is well known that aromatic isocyanates are more reactive than aliphatic or cycloaliphatic isocyanates. This could also explain the two different behaviors observed here. Indeed, due to the different reactivities, the diurethane OMO reacted with a cycloaliphatic isocyanate, in our case tIPDI, would produce less allophanates than that reacted with an aromatic isocyanate, here MDI. In the same way, less tIPDI is supposed to react with dissociated alcool, produced by the urethane dissociation at high temperature. This means that the isocyanate and alcohol functions originating in the OMO molecules will remain in a quasi equimolar ratio. Almost all the urethane linkages, dissociated during the reaction at high temperature can then be reformed, so that fewer monourethanes OM will be observed back at room temperature in the case of a reaction OMO + tIPDI.

\section{Conclusion}

Thanks to a model study, it was possible to clearly identify allophanates as the main products of reaction between a diurethane and di-or polyisocyanates at high temperature, without any catalyst and when the mixture is cooled to room temperature. Isocyanurates form only in very polar solvents during analysis but do not constitute a reaction product in bulk. When tIPDI is reacted with urethanes, less allophanates and monourethanes are formed, comparing with the reaction of OMO + MDI. Moreover, it has been shown that the combination of NMR and MALDI-TOF analysis can be a very useful characterization method.

These results prove the possibility to create some crosslinks, through allophanate functions withstanding these temperatures, by adding polyisocyanates to a TPU by reactive extrusion. This simple modification has already been used to improve the mechanical and thermal properties of such material[22, 23].

Financial support from Novéon (Frontonas-69 F) and Nexans (Lyon-69 F), together with fruitful advice and discussions with Mr Lagneaux, Mr Widawski, Mr Fournier and Mr Pinto, are gratefully acknowledged.

\section{References}

[1] Parodi F. Colin Booth and Colin Price. 1989; Pergamon Press: University of Manchester, UK. 387-404

[2] Sato M. J. Org. Chem. 1962; 27: 819.

[3] Schwetlick K., Noack R. J. Chem. Soc. Perkin Trans. 2 1995: 395-402.

[4] Wong S-W., Frisch K.C. J. Polym. Sci. Polym. Chemistry 1986; 24: 2877-2890.

[5] Wong S-W., Frisch K.C. J. Polym. Sci. Polym. Chemistry 1986; 24: 2867-2875.

[6] Kogon I.C. J. Am. Chem. Soc. 1956; 78: 4911-4914.

[7] Kogon I.C. J. Am. Chem. Soc. 1957; 79: 2253-2254.

[8] Kogon I.C. J. Org. Chem. 1959; 24 (1): 83-86.

[9] Furukawa M., Yokoyama T. J. Polym. Sci. Polym. Letters Ed. 1979; 17: 175-180.

[10] Sumi M., Chokki Y., Nakai Y., Nakabayashi M. ,Kanzawa T. Makromol. Chem. 1964; 78: 146-156.

[11] Okuto H. Makromol. Chem. 1965; 98: 148-163.

[12] Spirkova M., Kubin M., Dusek K. J. Macromol. Sci. - Chem. 1987; A24 (10): 1151-1166.

[13] Sebenik A., Osredkar U., Vizovisek I. J. Macromol. Sci. - Chem. 1986; A23 (3): 369-379.

[14] Joel D., Krüger R.P., Gnauck R. Plaste Kautsch. 1980; 27: 314.

[15] Wagner K. Angew. Chem. 1962; 74: 799.

[16] Joel D., Schulz G. Plaste Kautsch. 1985; 32: 151. 
[17] Kogon I.C. J. Org. Chem. 1958; 23: 1594.

[18] Bayer O. Das Diisocyanate-Polyadditions Verfahren, Carl Hanser Verlag. 1963; Muenchen,

[19] Yang W.P., Macosko C.W. ,Wellinghoff S.T. Polymer. 1986; 27 (1235-1240):

[20] Camberlin Y., Pascault J.P. J. Polym. Sci. Polym. Chemistry 1982; 20: 383-392.

[21] Lu Q., Hoye T.R. ,Macosko C.W. J. Polym. Sci. Polym. Chemistry 2002; 40: 2310-2328.

[22] Dassin S., Dumon M., Méchin F., Pascault J.P. Polym. Eng. Sci. 2002; 42: 1724-1739.

[23] GEMOPLAST. 1999 / 2000, FR 9907454, WO 00/75213A1.

[24] Burel F., Feldman A., Loutelier-Bourhis C., Bunel C. e-Polymers 2004; 011: 1-9.

[25] Anzuino G., Pirro A., Rossi O., Polo Friz L. J. Polym. Sci. Polym. Chemistry 1975; 13: 1657-1666.

[26] Matsui T., Kamatani H., Arimatsu Y., Kaji A., Hattori K. ,Suzuki H. J. Appl. Polym. Sci. 1991; 42: 24432452.

[27] Ketata N., Sanglar C., Waton H., Alamercery S., Delolme F., Paisse O., Raffin G., Grenier-Loustalot M.F. Polym and Polym Comp. 2004; in press.

[28] Kricheldorf H.R., Hull W.E. Makromol. Chem. 1981; 82: 1177-1196.

[29] Hatada K., Ute K., Oka K. Journal of Polymer Science: Part A: Polymer Chemistry 1990; 28: 3019-3027.

[30] Rochery M., Vroman I., Lam T.M. J. Macromol. Sci. - Pure Appl. Chem. 2000; A37 (3): 259-275.

[31] Bialas N., Höcker H. Makromol. Chem. 1990; 191: 1843-1852.

[32] Gérard J.F., Le Perchec P., Pham Q.T. Makromol. Chem. 1988; 189 (7): 1719-1737.

[33] Desilet S., Villeneuve S., Laviolette M., Auger M. J. Polym. Sci. Polym. Chemistry 1997; 35: 2991-2998. 
Table 1 : Thermal stability of different types of urethanes

Type of urethane group

Approximate upper stability temperature

$\begin{array}{cc}\text { Alkyl-NH-CO-O-Alkyl } & \sim 250^{\circ} \mathrm{C} \\ \text { Aryl-NH-CO-O-Alkyl } & \sim 200^{\circ} \mathrm{C} \\ \text { Alkyl-NH-CO-O-Aryl } & \sim 180^{\circ} \mathrm{C} \\ \text { Aryl-NH-CO-O-Aryl } & \sim 120^{\circ} \mathrm{C}\end{array}$




\section{Figure captions}

Figure 1 : Different reactions between NCO and OH groups. The kinetic rate constants of the reactions a, b, c and d are, respectively, $k_{a}, k_{b}, k_{c}$ and $k_{d}$.

Figure $2:$ Reactions of NCO groups in the presence of water

Figure 3 : Formation of OMO by the reaction between $n$-octanol and MDI.

Figure 4 : MALDI-TOF spectrum of tIPDI.

Figure 5 : Isocyanurate formation

Figure 6 : Expansion of the carbonyl region of ${ }^{13} \mathrm{C}$ NMR (DMSO-d6) spectrum of OMO+MDI, i/u $=1,192^{\circ} \mathrm{C}$ for $60 \mathrm{~min}$, non-neutralized sample a) acquisition time $\left.=28 \mathrm{~min}, \mathrm{~b}\right)$ acquisition time $=$ 3h47min, c) after 5 days.

Figure 7: SEC chromatograms of OMO+MDI, isocyanate/urethane $=1$, reacted at $192^{\circ} \mathrm{C}$.

Figure 8: Enlargements of (1) ${ }^{1} \mathrm{H}\left(\mathrm{NH}\right.$ region) and (2) ${ }^{13} \mathrm{C}(\mathrm{C}=\mathrm{O}$ region) NMR spectrum for a $\mathrm{OMO}+\mathrm{MDI}$ mixture, $\mathrm{i} / \mathrm{u}=1,192^{\circ} \mathrm{C}$ for $60 \mathrm{~min}$ a) non-neutralized sample b) sample neutralized with diethylamine

Figure 9 : MALDI-TOF spectrum of $\mathrm{OMO}+\mathrm{MDI}, \mathrm{i} / \mathrm{u}=1,192^{\circ} \mathrm{C}$, for $60 \mathrm{~min}$, non-neutralized.

Figure $10:{ }^{13} \mathrm{C}$ NMR $\left(\mathrm{CDCl}_{3}\right)$ spectrum of $\mathrm{OMO}+\mathrm{tIPDI}, \mathrm{i} / \mathrm{u}=1 / 2,170^{\circ} \mathrm{C}$, for $60 \mathrm{~min}($ sample neutralized with diethylamine). (i) impurity coming from THF.

Figure 11 : Two different allophanates expected by reacting OMO with tIPDI

Figure 12 : Change with time of the relative amounts of isocyanate $(\bullet)$, urethane $(\diamond)$ and allophanate

( - ) functions present in reactions at equimolar isocyanate over urethane ratio, at $170^{\circ} \mathrm{C}$, a) $\mathrm{OMO}+$ MDI, b) OMO + tIPDI.

Figure 13 : SEC curves of OMO + MDI mixture (---), at i/u=1, $190^{\circ} \mathrm{C}, 60 \mathrm{~min}$ and $\mathrm{OMO}+\mathrm{tIPDI}$ mixture (-), at $\mathrm{i} / \mathrm{u}=1,210^{\circ} \mathrm{C}, 120 \mathrm{~min}$. 
a. urethane formation

$$
\mathrm{R}^{1} \longrightarrow \mathrm{NCO} \stackrel{\mathrm{R}^{2}-\mathrm{OH}}{\longrightarrow \cdots \cdots} \quad \mathrm{R}^{2}-\mathrm{O}-\mathrm{C} \longrightarrow \mathrm{N}-\mathrm{R}^{1}
$$

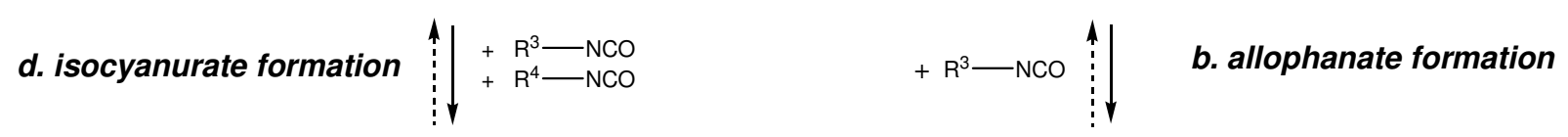<smiles>[R]OC(=O)N([R])C(=O)NP</smiles>

Figure 1 : Different reactions between NCO and OH groups. The kinetic rate constants of the reactions a, b, c and d are, respectively, $k_{a}, k_{b}, k_{c}$ and $k_{d}$.

Figure 1 - 
a. urea formation

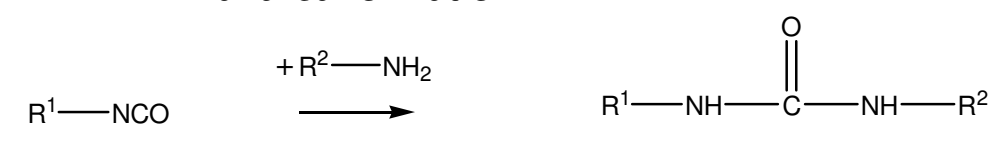

c. amine formation

Figure 2 : Reactions of NCO groups in the presence of water

Figure 2 - 


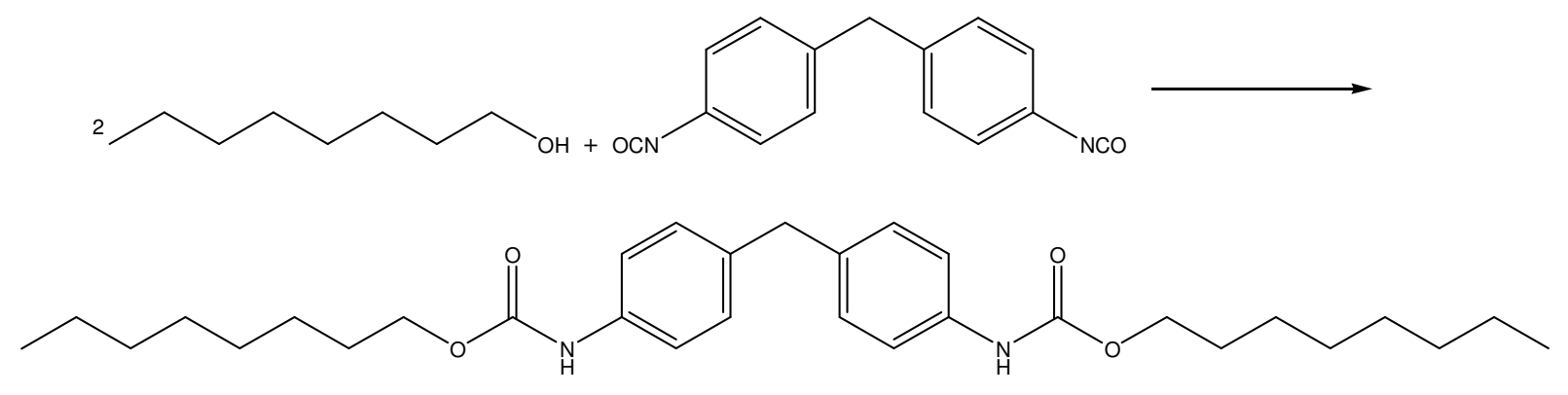

Figure 3 : Formation of OMO by the reaction between $n$-octanol and MDI.

Figure 3 - 


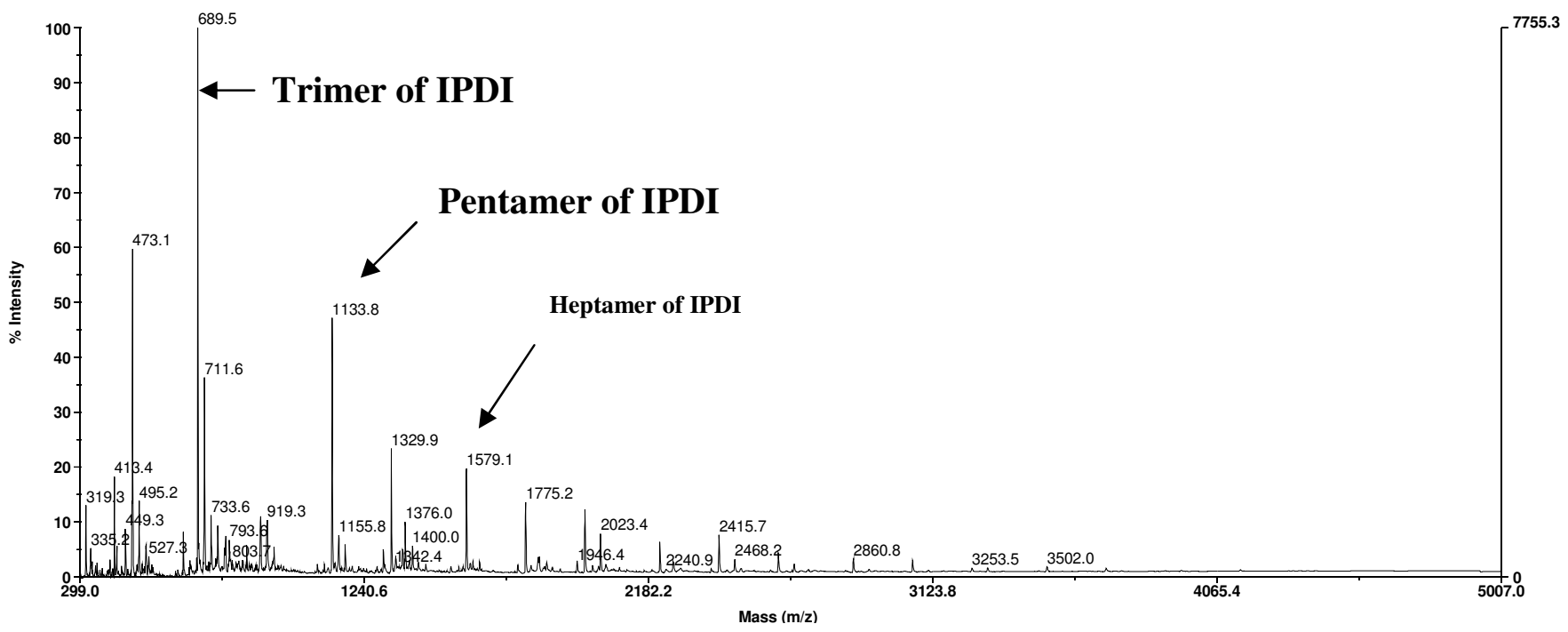

Figure 4 : MALDI-TOF spectrum of tIPDI.

Figure 4 - 


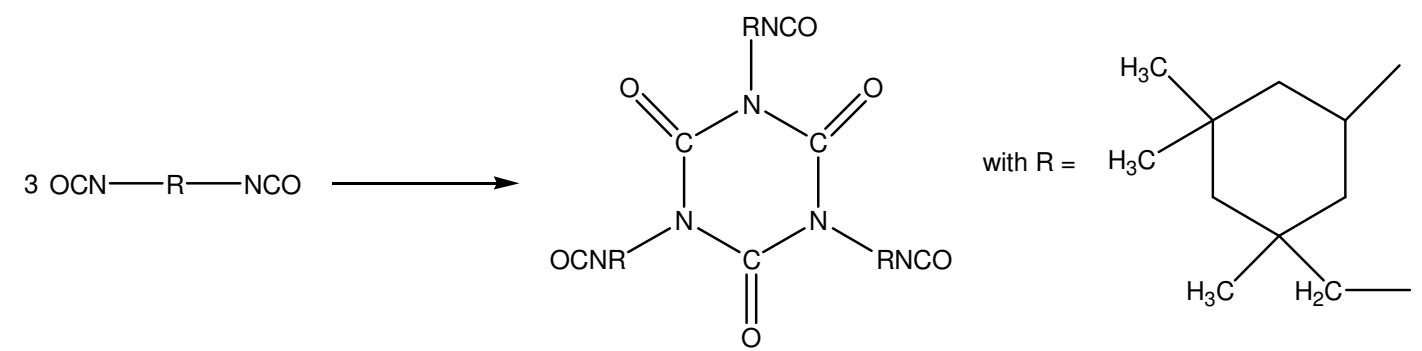

Figure 5 : Isocyanurate formation

Figure 5 - 


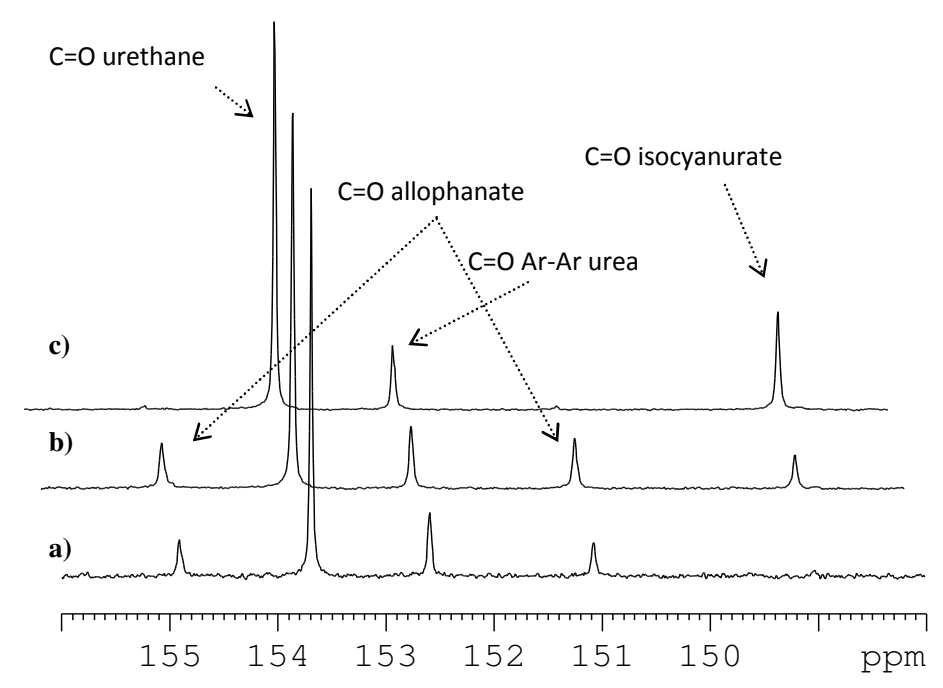

Figure 6 : Expansion of the carbonyl region of ${ }^{13} \mathrm{C}$ NMR (DMSO- $d 6$ ) spectrum of OMO+MDI, i/u $=1,192^{\circ} \mathrm{C}$ for $60 \mathrm{~min}$, non-neutralized sample a) acquisition time $\left.=28 \mathrm{~min}, \mathrm{~b}\right)$ acquisition time $=3 \mathrm{~h} 47 \mathrm{~min}, \mathrm{c})$ after 5 days.

Figure 6 - 


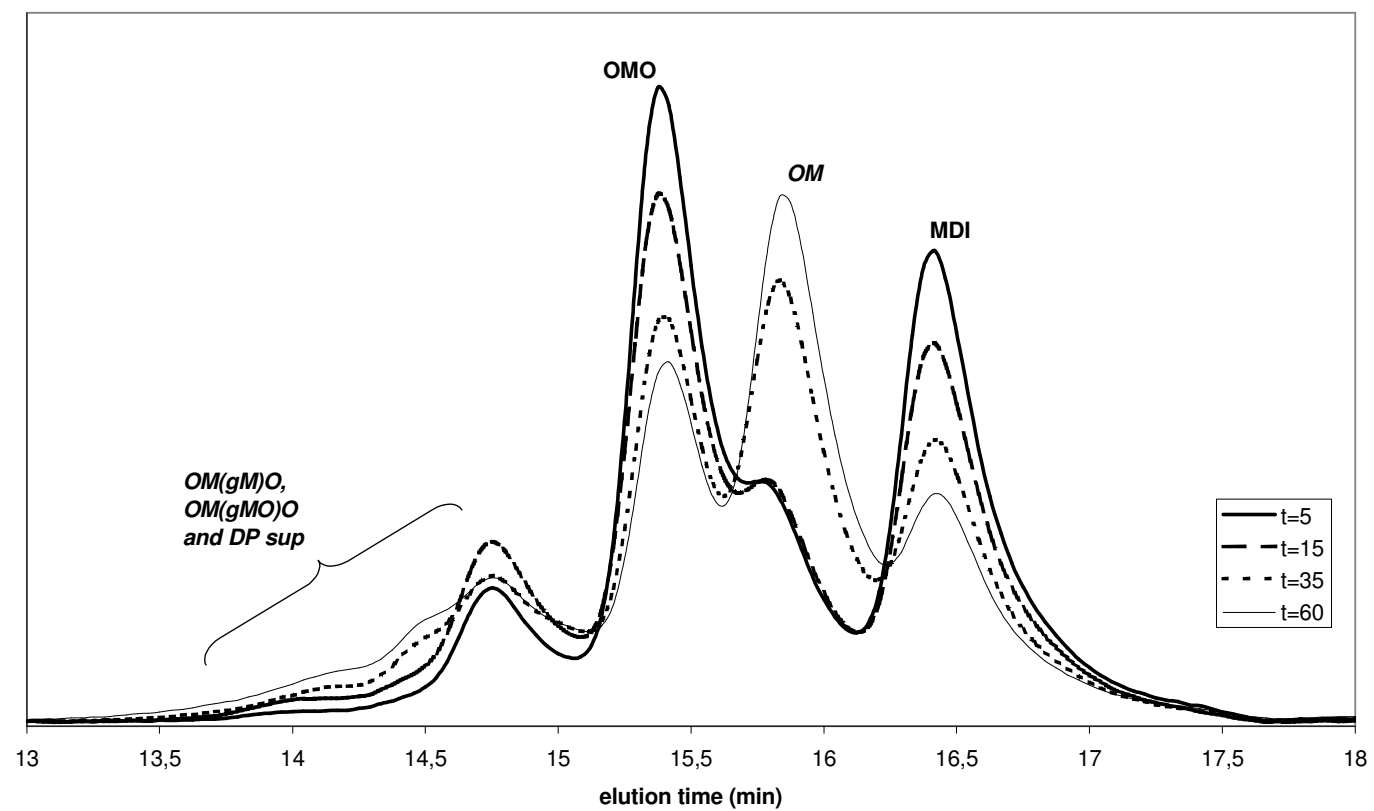

Figure 7: SEC chromatograms of OMO+MDI, isocyanate/urethane $=1$, reacted at $192^{\circ} \mathrm{C}$.

Figure 7 - 


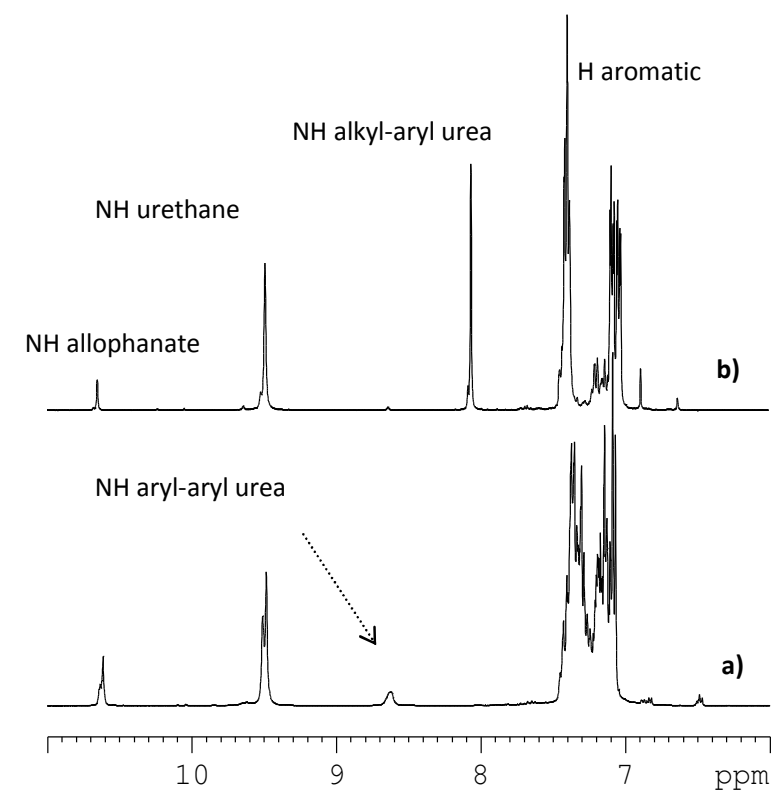

(1)

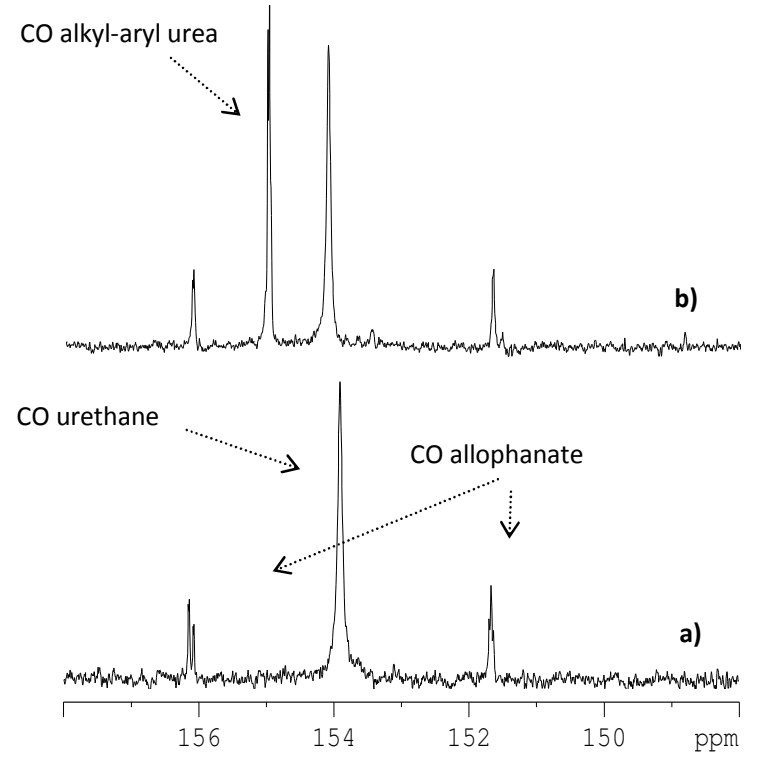

(2)

Figure 8: Enlargements of (1) ${ }^{1} \mathrm{H}\left(\mathrm{NH}\right.$ region) and $(2){ }^{13} \mathrm{C}(\mathrm{C}=\mathrm{O}$ region $) \mathrm{NMR}$ spectrum for a $\mathrm{OMO}+\mathrm{MDI}$ mixture, $\mathrm{i} / \mathrm{u}=1,192^{\circ} \mathrm{C}$ for $60 \mathrm{~min}$ a) non-neutralized sample b) sample neutralized with diethylamine

Figure 8 - 


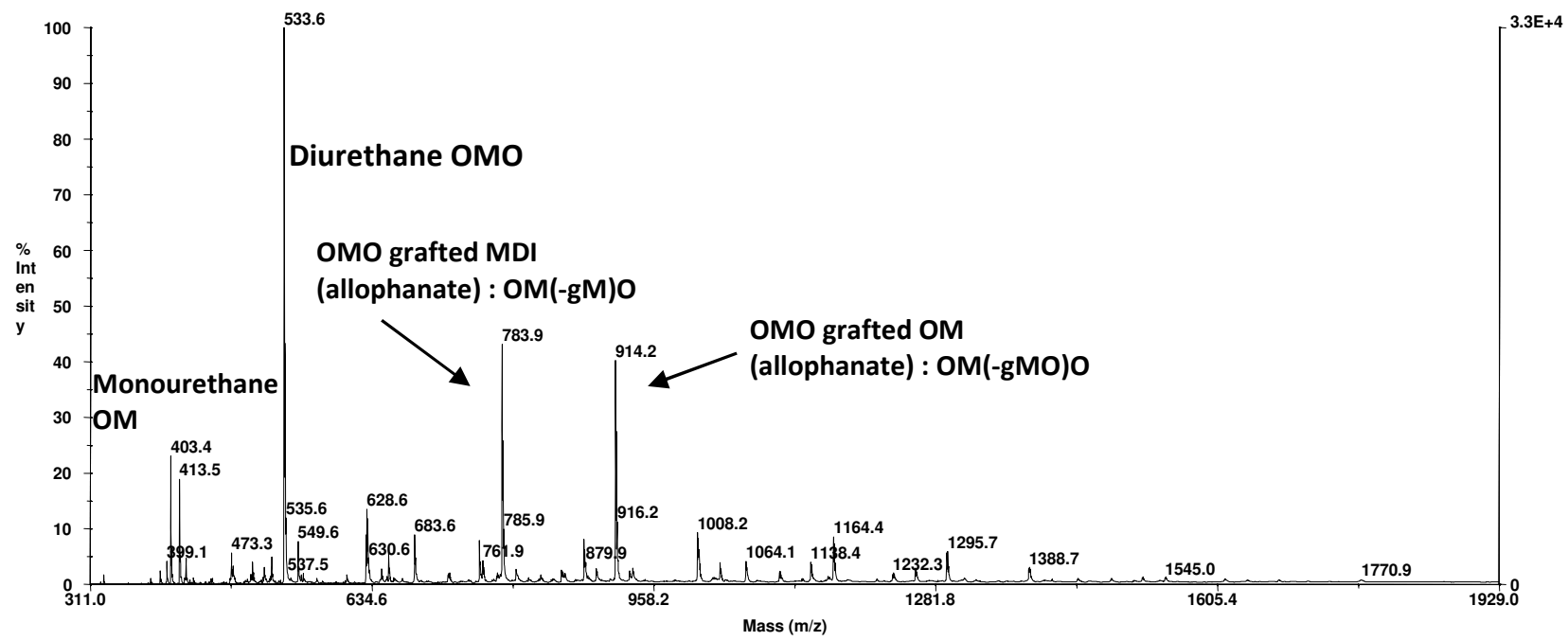

Figure 9 : MALDI-TOF spectrum of OMO+MDI, i/u $=1,192^{\circ} \mathrm{C}$, for $60 \mathrm{~min}$, non-neutralized.

Figure 9 

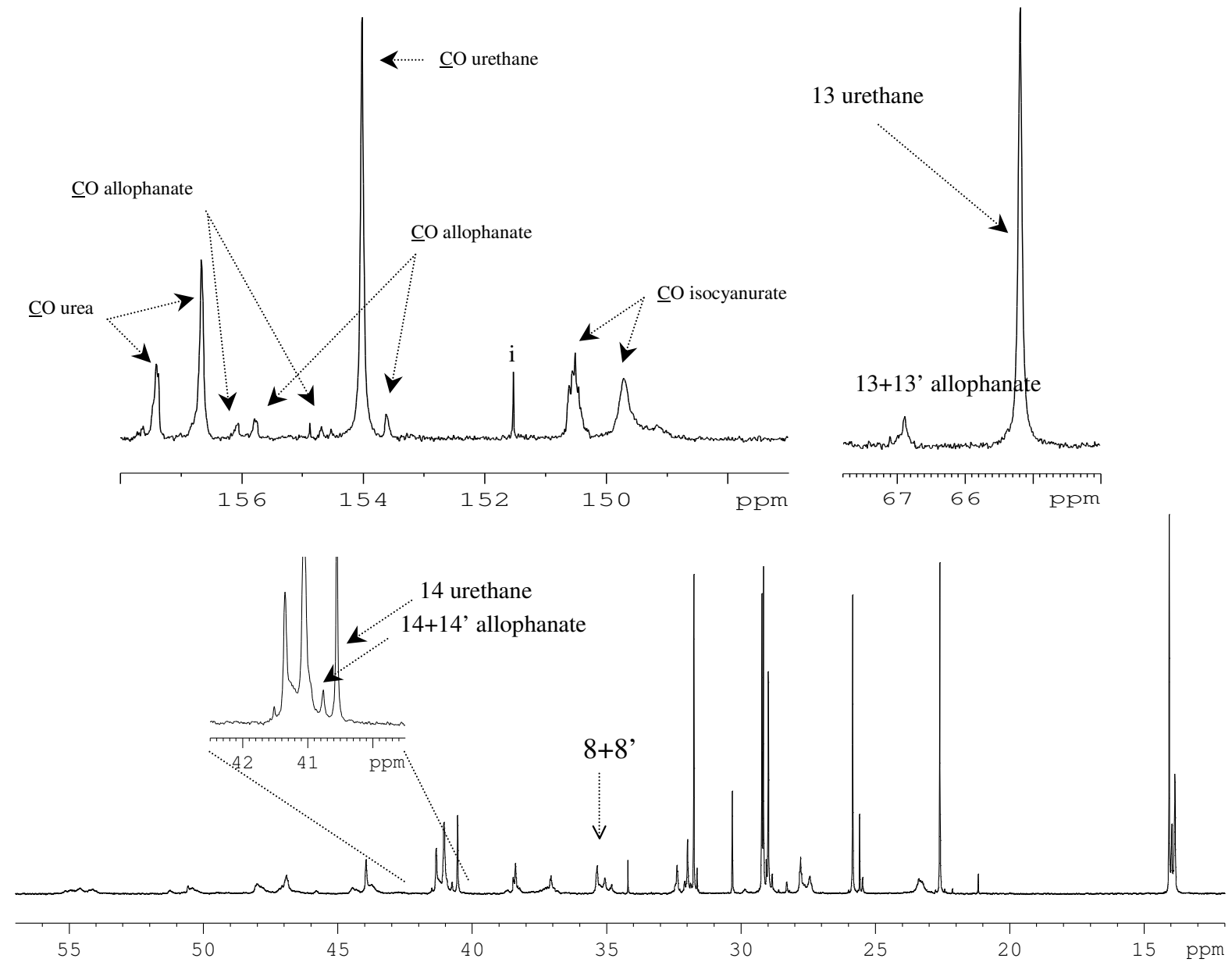

Figure $10:{ }^{13} \mathrm{C} \mathrm{NMR}\left(\mathrm{CDCl}_{3}\right)$ spectrum of $\mathrm{OMO}+\mathrm{tIPDI}, \mathrm{i} / \mathrm{u}=1 / 2,170^{\circ} \mathrm{C}$, for $60 \mathrm{~min}$ (sample neutralized with diethylamine). (i) impurity coming from THF.

Figure 10 


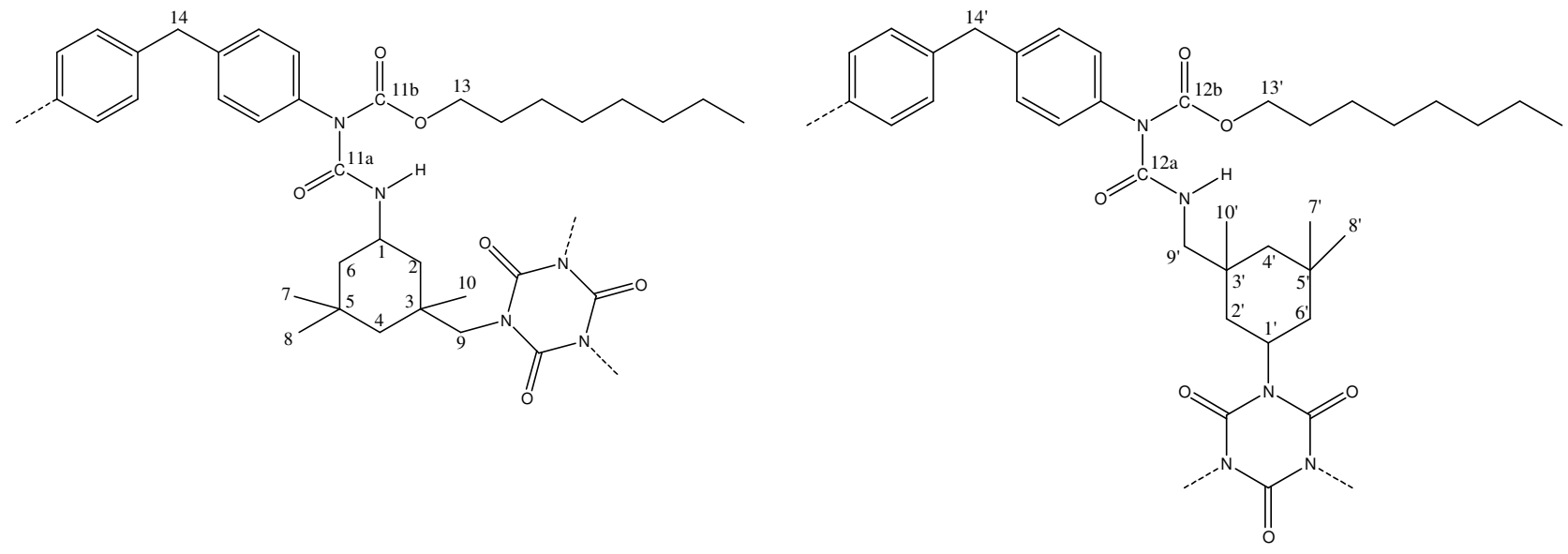

Figure 11 : Two different allophanates expected by reacting OMO with tIPDI

Figure 11 

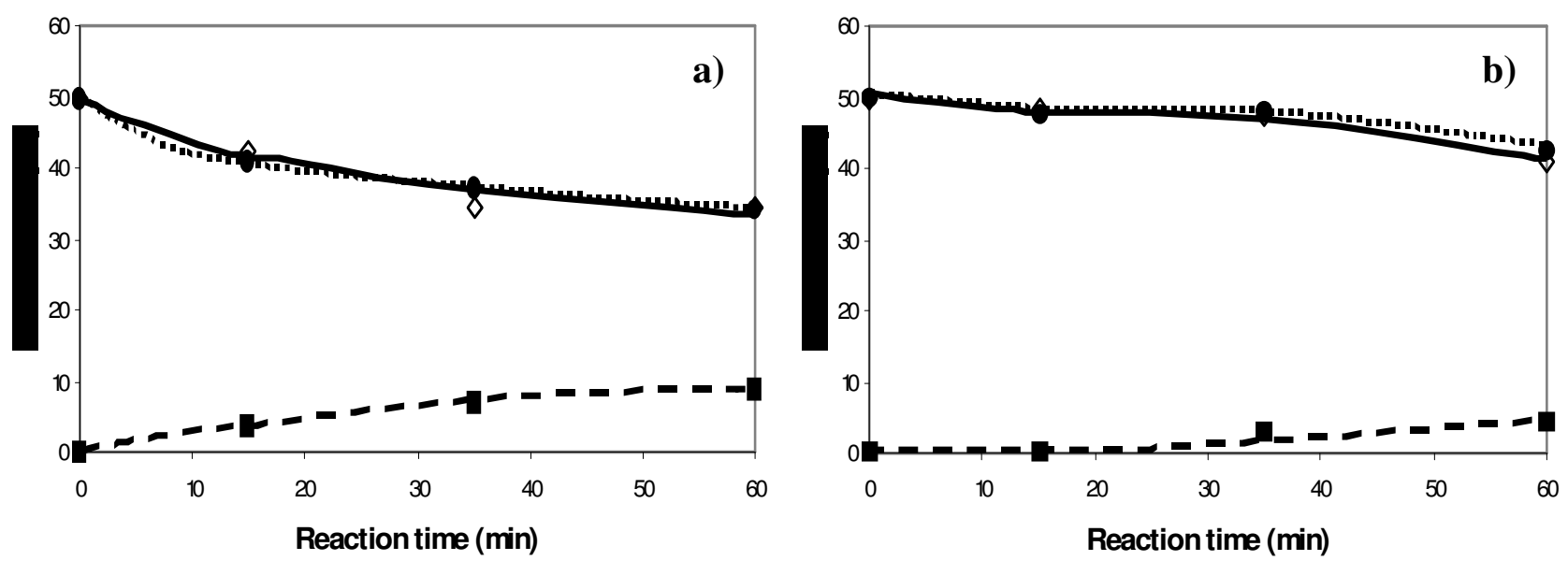

Figure 12 : Change with time of the relative amounts of isocyanate $(\bullet)$, urethane $(\diamond)$ and allophanate ( $\boldsymbol{\square})$ functions present in reactions at equimolar isocyanate over urethane ratio, at $170^{\circ} \mathrm{C}$, a) $\mathrm{OMO}+\mathrm{MDI}$, b) OMO + tIPDI. 


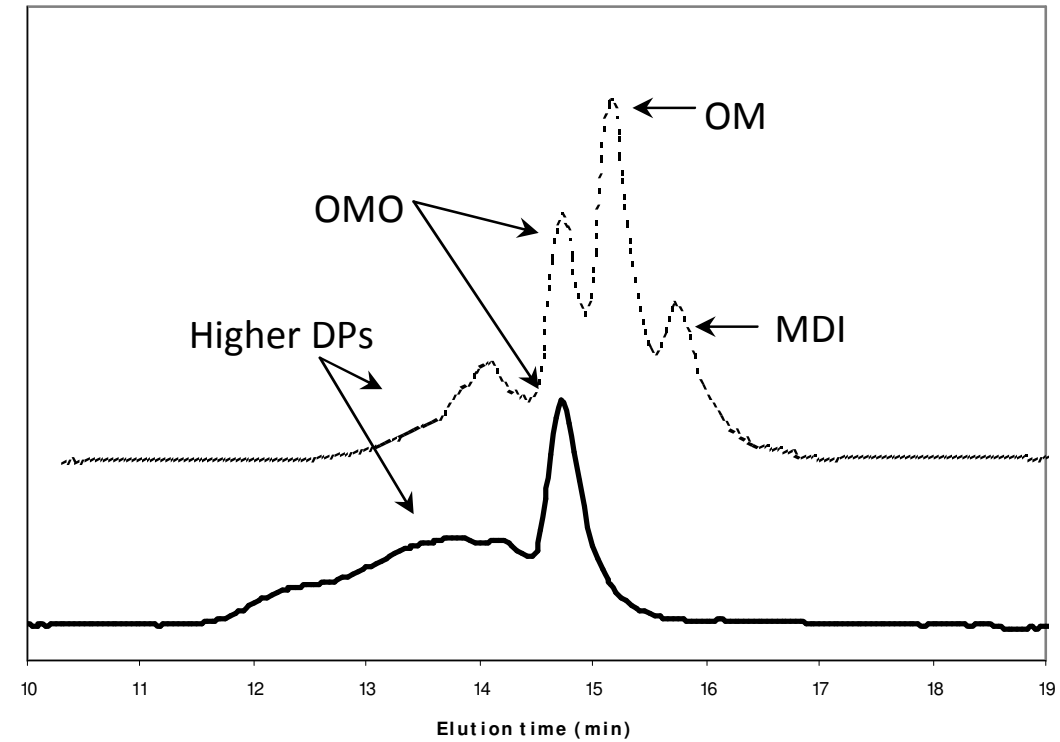

Figure 13 : SEC curves of OMO + MDI mixture (---), at i/u=1, $190^{\circ} \mathrm{C}, 60 \mathrm{~min}$ and $\mathrm{OMO}+\mathrm{tIPDI}$ mixture (-), at $\mathrm{i} / \mathrm{u}=1,210^{\circ} \mathrm{C}, 120 \mathrm{~min}$.

Figure 13 - 